\title{
Stop press
}

\author{
Press embargoes of research articles can serve journals, researchers and journalists - as long as \\ everyone plays by, and understands, the rules.
}

No one likes to open the pages of their favourite chemistry journal and find that someone else has published the work that they are feverishly rushing to complete. Scientists have worried about being scooped since the time of Newton and Leibniz, and probably before that too. With science seeming to be a game of ever-higher stakes, this is unlikely to change in the near future - although plant-cell biologist Sean Cutler showed one particularly enlightened and altruistic way of avoiding this pitfall ${ }^{1,2}$. He invited all his potential rivals to collaborate on a research project, and further showed that cooperation can pay off by publishing the work in a highprofile journal ${ }^{3}$.

High-profile journals are notoriously as worried - if not more so - about being scooped as the researchers hoping to publish their work in them. But it's not just other research groups that journals are looking over their shoulder for; they are also concerned that over-eager journalists may report the work before the peer-reviewed article has been published. Not only does this reduce the novelty and impact of the journal's article, but it can lead to inaccurate reporting if journalists and their expert sources cannot see the paper in question. More worrying are examples in medical research, where unprepared doctors are bombarded with questions from concerned patients who have absorbed the news before the doctors have been able to read the science behind it.

This is one of the reasons why many journals have an embargo policy, releasing copies of their articles to journalists before they are due to be published. In return for this service, journalists agree to abide by an embargo: they will not publish their stories before an agreed time and date. This system has been in place for some time, but it is not without its critics. Some of the arguments against embargoes suggest that it reduces the amount of original investigative journalism and increases 'churnalism', where news articles are little more than copied-and-pasted press releases. This is not the forum for a discussion of those rights or wrongs, but interested readers can follow the debate and keep up to date with broken embargoes at the Embargo Watch blog (http://embargowatch. wordpress.com).

We routinely make our papers available to members of the press about a week before they are published. During this embargo period, authors are allowed - encouraged - to speak to any journalists who contact them. At other times before the publication date, however, this is discouraged and, as outlined below, could result in a paper not being published.

The other end of journals' embargo policy is known as the Ingelfinger rule. Named after a former editor of the New England Journal of Medicine (NEJM), this states that for an article to be published in the journal it must not have previously appeared anywhere else - including news media. The policy ${ }^{4}$ of the Nature Publishing Group (NPG) - to which Nature Chemistry belongs - is, in part, similar: "Material submitted to Nature journals must not be discussed with the media [...]. We reserve the right to halt the consideration or publication of a paper if this condition is broken."

Communicating with other scientists, through such mechanisms as conference presentations, preprint servers or departmental seminars, is not prohibited. As the policy states", "Nature journals do not wish to hinder communication between scientists." Any policy that did so would be counter-productive for all concerned. Of course, journalists may attend conferences or browse preprint servers and find stories that way - many scientists may indeed wish that more journalists did so and became better acquainted with the coal face of research. In these relatively rare cases, journalists have not agreed to any embargo and may therefore publish stories, but we ask that our authors do not discuss their work or seek to encourage premature publication.

Mainstream press coverage of science is often criticised for a number of perceived failings, a common one being an overreliance on press releases ${ }^{5}$. And when these press releases come with a generous portion of hype attached that makes it into the final piece, it can leave the more expert reader groaning with frustration, or the less expert reader confused as to which breakthroughs are real and which require more imagination. But well-written press releases, which soberly and responsibly explain the context and potential impact of new research, should act as a useful starting point on which journalists can base their own articles.

The positive side of embargoes and press releases are that they can help to produce more and better coverage of science in the mainstream media. Properly handled, they give journalists time to not only research topics they may not have covered before, but also crucially to canvass other experts in the area to present a balanced story. From a researcher's point of view, embargoes can also produce more coverage because few journalists want to be scooped on their own beat, so a single piece of work may be covered in several different outlets. An original investigation by a single journalist is less likely to receive coverage from his or her peers.

Although difficult to quantify accurately, a study has shown that mainstream press coverage also seems to increase the number of citations a paper receives ${ }^{6}$. Briefly, a group compared the citations to papers in the NEJM that had been covered by the New York Times with citations to NEJM papers that had not received such coverage. Thanks to a threemonth strike by the New York Times, during which a 'newspaper of record' was produced but not distributed, they had a perfect control. The findings indicate that articles covered by the newspaper received around $70 \%$ more citations than the controls.

Whether this finding is applicable to all journals and indeed all areas of science is debatable, but a recent Nature Chemistry paper ${ }^{7}$ was the result of a collaboration triggered by newspaper coverage $e^{8,9}$ of a research article ${ }^{10}$. And seeing well-reported science covered by mainstream news sources is a worthy goal for anyone involved in science, and particularly chemistry, suffering as it does from much negative press. Although the NPG embargo policy may seem harsh on first inspection, it is in place for good reasons and the appropriate use of accurate, embargoed press releases offers benefits to all parties - researchers, journalists and journals - alike.

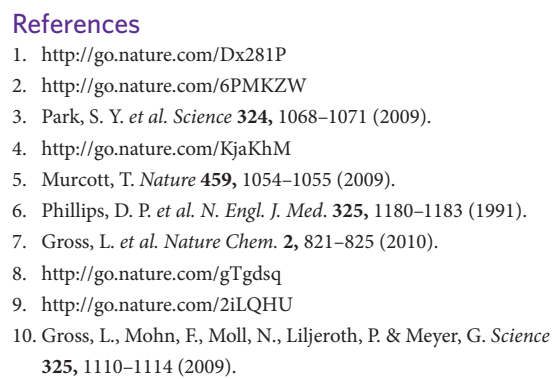

Corrected online: 16 November 2010 


\section{Correction}

In the version of the Editorial 'Stop press'

originally published (Nature Chem. 2, 791; 2010),

the name of Leibniz was mis-spelled. This has

now been corrected in the HTML and PDF

versions: 16 November 2010 